\title{
Salivary detection of COVID-19: clinical performance of oral sponge sampling for SARS-CoV-2 testing
}

\author{
Jacques Boutros $\mathbb{C}^{1}$, Jonathan Benzaquen ${ }^{1,2}$, Charles Hugo Marquette $\mathbb{B}^{1,2}$, Marius Ilié ${ }^{2,3}$, \\ Mickelina Labaky ${ }^{4}$, Didier Benchetrit ${ }^{4}$, Thibaut Lavrut ${ }^{5}$, Sylvie Leroy ${ }^{1,6}$, Richard Chemla ${ }^{7}$, Michel Carles ${ }^{8}$, \\ Virginie Tanga ${ }^{3}$, Charlotte Maniel ${ }^{1}$, Olivier Bordone ${ }^{3}$, Maryline Allégra ${ }^{3}$, Virginie Lespinet ${ }^{3}$, Julien Fayada ${ }^{3}$, \\ Jennifer Griffonnet ${ }^{1}$, Véronique Hofman ${ }^{2,3}$ and Paul Hofman ${ }^{2,3}$
}

${ }^{1}$ Dept of Pulmonary Medicine and Thoracic Oncology, Université Côte d’Azur, Centre Hospitalier Universitaire de Nice, FHU OncoAge, Nice, France. ${ }^{2}$ Université Côte d'Azur, CNRS, INSERM, Institute of Research on Cancer and Aging, Nice, France. ${ }^{3}$ Laboratory of Clinical and Experimental Pathology (LPCE), Université Côte d'Azur, FHU OncoAge, Centre Hospitalier Universitaire de Nice, Biobank (BB-003300025), Nice, France. ${ }^{4}$ SYNLAB Barla, Nice, France. ${ }^{5}$ Université Côte d’Azur, Centre Hospitalier Universitaire de Nice, Laboratoire de Virologie, CHU de Nice, Nice, France. ${ }^{6}$ CNRS UMR 7275 - Institut de Pharmacologie Moléculaire et Cellulaire, Université Côte d'Azur, Nice, France. ${ }^{7}$ Ville de Nice, Nice, France. ${ }^{8}$ Dept of Infectious Diseases, Université Côte d'Azur, Centre Hospitalier Universitaire de Nice, Nice, France.

Corresponding author: Charles Marquette (marquette.c@chu-nice.fr)

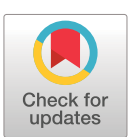

Copyright @The authors 2021

This version is distributed under the terms of the Creative Commons Attribution NonCommercial Licence 4.0. For commercial reproduction rights and permissions contact permissions@ersnet.org

This article has supplementary material available from openres.ersjournals.com

Received: 16 June 2021 Accepted: 17 Sept 2021

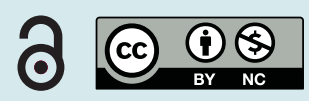

Shareable abstract (@ERSpublications)

Oral sampling for \#SARSCoV2 RT-PCR is an easy-to-perform, straightforward self-administered sampling technique that has a sensitivity of up to $93.2 \%$ in symptomatic patients and $71 \%$ in close contact subjects https://bit.ly/3AKRj2U

Cite this article as: Boutros J, Benzaquen J, Marquette $\mathrm{CH}$, et al. Salivary detection of COVID-19: clinical performance of oral sponge sampling for SARS-CoV-2 testing. ERJ Open Res 2021; 7: 003962021 [DOI: 10.1183/23120541.00396-2021].

\section{Abstract}

Background The current diagnostic standard for coronavirus disease 2019 (COVID-19) is reverse transcriptase-polymerase chain reaction (RT-PCR) testing with nasopharyngeal (NP) swabs. The invasiveness and need for trained personnel make the NP technique unsuited for repeated community-based mass screening. We developed a technique to collect saliva in a simple and easy way with the sponges that are usually used for tamponade of epistaxis. This study was carried out to validate the clinical performance of oral sponge (OS) sampling for severe acute respiratory syndrome coronavirus 2 (SARS-CoV-2) testing.

Methods Over a period of 22 weeks, we collected prospectively 409 paired NP and OS samples from consecutive subjects presenting to a public community-based free screening centre. Subjects were referred by their attending physician because of recent COVID-19 symptoms $(n=147)$ or by the contact tracing staff of the French public health insurance because they were considered as close contacts of a laboratoryconfirmed COVID-19 case $(n=262)$.

Results In symptomatic subjects, RT-PCR SARS-CoV-2 testing with OS showed a 96.5\% (95\% CI: 89.694.8) concordance with NP testing, and a 93.2\% (95\% CI: 89.1-97.3) sensitivity when using the IdyllaTM platform and a sensitivity of $76.3 \%$ (95\% CI: 69.4-83.2) on the Synlab Barla laboratory platform. In close contacts the NP-OS concordance (93.8\%, 95\% CI: 90.9-96.7) and OS sensitivity (71.9\%, 95\% CI: 66.5-77.3) were slightly lower.

Conclusion These results strongly suggest that OS testing is a straightforward, low-cost and highthroughput sampling method that can be used for frequent RT-PCR testing of COVID-19 patients and mass screening of populations.

\section{Introduction}

To date, reverse transcriptase-polymerase chain reaction (RT-PCR) testing of nasopharyngeal swab specimens (NP) is the gold standard for the detection of severe acute respiratory syndrome coronavirus 2 (SARS-CoV-2) [1-3]. While its specificity can be as high as $100 \%$, its sensitivity ranges from 42 to $98 \%$ during the first 10 days of coronavirus disease 2019 (COVID-19) [4, 5] and depends on the operator and on the moment the sampling is performed during the course of the infection. RT-PCR on NP, known as 
being of "high analytical sensitivity", is particularly well suited for symptomatic patients. However, in the context of a pandemic, when mass screening or repeated testing is required, the use of NP for RT-PCR is not appropriate since its acceptability is debated and its implementation requires time and dedicated trained staff $[6,7]$.

Antigen-detecting rapid diagnostic tests (Ag-RDT), also-called lateral-flow tests, are quick, simple, inexpensive and allow the decentralisation of testing at the point of care. These tests can be performed on NP but also on anterior nasal or mid-turbinate samplings which require minimal supervision. Their sensitivity is high in symptomatic patients, which is crucial for triage in hospital emergency departments, but is low in asymptomatic subjects [8,9]. In these latter individuals they can be categorised as high-frequency tests with low analytical sensitivity as reported previously by Mina et al. [6].

Oral sampling offers a promising alternative to NP [10]. Various pathophysiological pathways explain the presence of SARS-CoV-2 in saliva of patients with COVID-19 [11-13]. Tests with saliva involve amplification of viral RNA by RT-PCR or by reverse transcriptase loop-mediated isothermal amplification (RT-LAMP). These tests are noninvasive, easily repeatable and can be performed with or even without assistance, leading in the latter case to a lower risk of contamination by nursing staff. RT-PCR on saliva samples has been approved in Japan since June 2020 and in the USA since October 2020. Following the publication of an umbrella review [14] including 10 meta-analyses [10] as well as trials meeting predefined quality criteria, the French "Haute Autorité de Santé" [15] recently retained the indication of RT-PCR testing on saliva in the following three situations: 1) on symptomatic patients as a second-line alternative to NP when NP is difficult or impossible (deviation of the nasal septum, very young patients, patients with psychiatric disorders, etc.); 2) on contact persons as a second-line alternative to NP for whom NP is difficult or impossible; and 3) in the first instance as part of targeted mass screening, particularly if it is repeated regularly such as in schools, universities, for staff in healthcare establishments, in nursing homes, etc. From a practical point of view, saliva sampling should be performed $>30$ minutes after the last drink, food, cigarette/e-cigarette, tooth brushing or mouth rinsing [16]. Saliva spit into a dry and sterile bottle is preferred; otherwise, saliva is collected using a dedicated system. Based on our research on the respiratory epithelium and on COVID-19 [17-20], we aimed to investigate the concordance of RT-PCR SARS-CoV-2 testing using oral sponge (OS) as compared to NP testing and its sensitivity for symptomatic subjects and close contacts.

\section{Methods}

\section{Study design and participants}

The present study was conducted on a prospective cohort of consecutive volunteers at the Nice-Côte d'Azur Metropolis community-based COVID-19 centre (Nice, France), accessible for free screening to the general population.

During the first part of the study (September 21, 2020 to January 6, 2021) we enrolled adults referred by their attending physician because of recent ( $\leqslant 2$ weeks) symptoms of COVID-19. During the second part of the study (February 6 to March 8, 2021) we enrolled adults referred by the contact tracing staff of the French public health insurance [21], because they were considered as close contacts of a laboratory-confirmed COVID-19 case (figure 1).

\section{Procedures}

\section{Specimen collection}

After signing an informed consent to participate, all volunteers were interviewed and underwent paired NP and OS sampling in a random order. Disposable NP nylon swabs (type A-04; Jiangsu Han-Heng Medical Technology Co., Ltd., Changzhou, China) were eluted into a vial containing viral transport medium. Small hydroxylated polyvinyl acetate (PVA) sponges (Merocel ${ }^{\circledR}$ Standard Dressing, réf 400400; Medtronic, Dublin Ireland), usually used for tamponade of epistaxis, were placed in the mouth for 1 minute and inserted into a sterile collection tube by the subjects themselves. No instructions were given regarding the need to fast, to have chewed gum or smoked a cigarette/e-cigarette. NP and OS were received within $4 \mathrm{~h}$ at the laboratory.

\section{Detection of SARS-COV-2 RNA On NP samples}

All NP samples were sent to the Synlab Barla laboratory (Nice, France), a private biological analysis laboratory that is under contract with the Nice-Côte d'Azur Metropolis for COVID-19 screening tests. These samples underwent RT-PCR using the ORF1ab and N genes Da An Gene DA0992-Detection Kit for 2019-nCoV (Da An Gene Co., Ltd., Sun Yat-sen University, Guangzhou, China). For logistical reasons, this laboratory switched to the transcription mediated amplification (TMA) technique to detect 


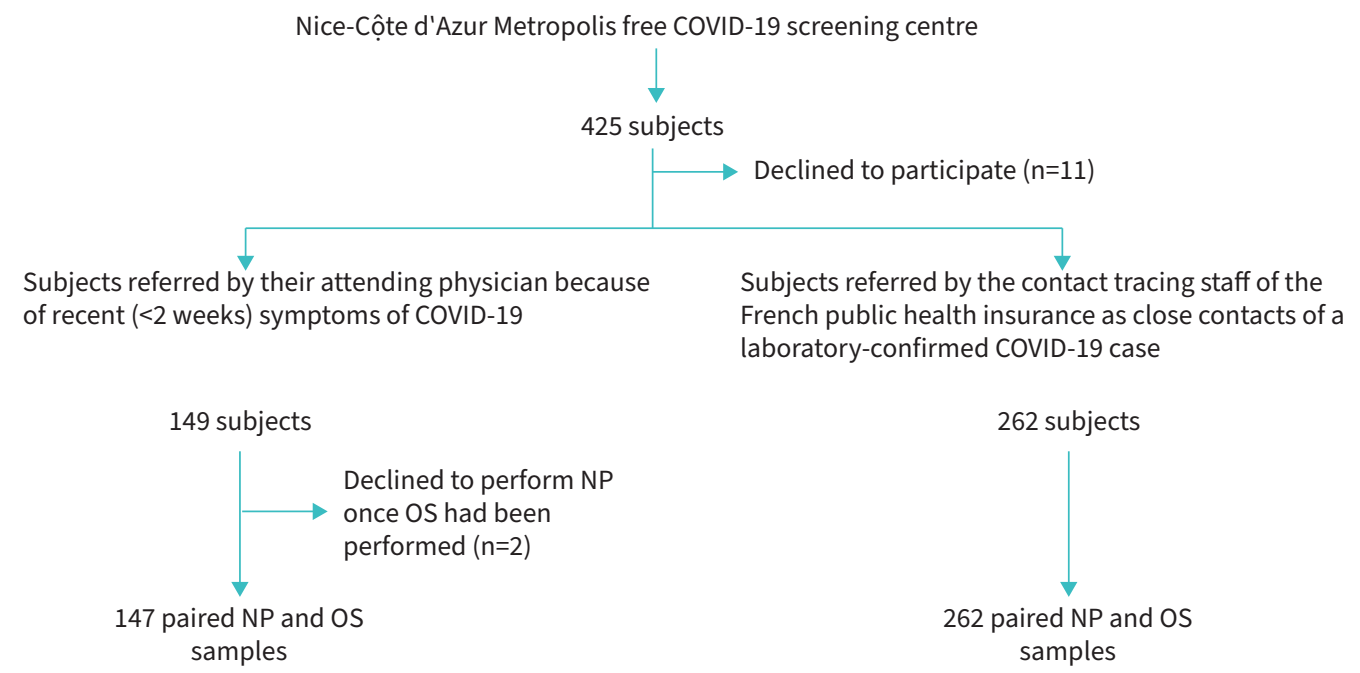

FIGURE 1 Trial profile. COVID-19: coronavirus disease 2019; NP: nasopharyngeal swab; OS: oral sponge.

SARS-CoV-2 RNA on NP samples during the second part of the study (symptom-free close contacts). According to the guidelines of the French Society for Microbiology [22] for RT-PCR, the result was considered positive when the cycle threshold $(\mathrm{Ct})$ value for the $\mathrm{N}$ and/or Orf1b genes was $\leqslant 36$. For TMA the result was considered as positive when the relative light unit (RLU) was above 850.

\section{Detection of SARS-COV-2 RNA on OS samples}

Upon arrival at the Laboratory of Clinical and Experimental Pathology (LPCE), the sponges were placed in the body of a syringe and the liquid was squeezed out of the sponge by pressing the plunger. $200 \mu \mathrm{l}$ of the OS eluate was pipetted with a sterile tip (reference 134000; D. Dutscher, Bernolsheim, France), placed individually into Idylla SARS-CoV-2 test cartridges (reference A1043/6; Biocartis, Mechelen, Belgium) and underwent fully automated nucleic acid testing including extraction, amplification and detection in a single-use cartridge as described previously [23]. The residual volume OS eluate was immediately aliquoted. According to the manufacturer, the Idylla SARS-CoV-2 test provides a qualitative result for the presence or absence of SARS-CoV-2 RNA with a corresponding quality status. The Biocartis SARS-CoV-2 test included two genes ( $\mathrm{N}$, Orf1b) covered by five PCR targets (two $\mathrm{N}$ targets and three Orf1b targets). A positive result required at least two amplified $\mathrm{N}$ targets (by setting a quantification cycle (Cq) of 41.9) and/or at least one or more amplified Orf1b targets. As Orf1b is highly specific, no threshold was required for this gene.

\section{External validation of SARS-COV-2 RNA detection on OS samples}

All OS eluates were sent to the Synlab Barla laboratory and underwent RT-PCR using the ORF1ab and N genes Da An Gene DA0992-Detection Kit as described above for NP. No threshold was used to define a positive result for OS. During the first part of the study (symptomatic subjects), this external validation was carried out on OS aliquots stored at $-80^{\circ} \mathrm{C}$ in the Nice COVID-19 biobank [18]. During the second part of the study, external validation was carried out on fresh specimens.

The different analyses were processed in a double-blind way: the results of the reference standard test were unavailable to the readers of the index test and vice versa.

\section{Outcomes}

The primary outcome was the clinical performance of OS compared to NP for SARS-CoV-2 screening in symptomatic and close contact subjects. For each group (symptomatic versus close contacts) we extracted the number of individuals positive for SARS-CoV-2 in a) both NP and OS, b) those positive only with NP, c) those positive only with OS and d) those negative with both NO and OS (table 1). From these data, we calculated the concordance of the two types of sample: $(a+d) /(a+b+c+d)$. We also calculated the sensitivity of the test on each type of sample. The estimation of the sensitivity of a test requires a reference diagnosis. Since NP sampling has been shown to produce false negatives by RT-PCR, sensitivities for NP and OS are defined here respectively as $(\mathrm{a}+\mathrm{b}) /(\mathrm{a}+\mathrm{b}+\mathrm{c})$ and $(\mathrm{a}+\mathrm{c}) /(\mathrm{a}+\mathrm{b}+\mathrm{c})$, considering as a true positive any individual 
TABLE 1 Clinical performance of oral sponges (OS) compared to nasopharyngeal swabs (NP) for SARS-CoV-2 screening (LPCE, Idylla platform)

\begin{tabular}{|c|c|c|c|c|c|c|c|c|}
\hline & $\begin{array}{c}\mathrm{NP}+ \\
\mathrm{OS}+ \\
a\end{array}$ & $\begin{array}{l}\mathrm{NP}+ \\
\mathrm{OS}- \\
b\end{array}$ & $\begin{array}{l}\text { NP - } \\
\text { OS + } \\
\quad C\end{array}$ & $\begin{array}{l}\text { NP - } \\
\text { OS - } \\
\quad d\end{array}$ & $\begin{array}{c}\text { Total } \\
n=a+b+c+d\end{array}$ & $\begin{array}{l}\text { Concordance \% } \\
(a+d) / n(95 \% \mathrm{Cl})\end{array}$ & $\begin{array}{l}\text { Sensitivity of NP \% } \\
(a+b) /(a+b+c)(95 \% \mathrm{Cl})\end{array}$ & $\begin{array}{l}\text { Sensitivity of OS \% } \\
(a+c) /(a+b+c)(95 \% \mathrm{Cl})\end{array}$ \\
\hline Symptomatic subjects & 54 & 4 & 1 & 88 & 147 & $96.5(93.5-99.5)$ & $98.3 \%(96.2-100)$ & $93.2^{\#}(89.1-97.3)$ \\
\hline Close contact subjects & 41 & 16 & 0 & 205 & 262 & $93.8(90.9-96.7)$ & 100 & $71.9(66.5-77.3)$ \\
\hline
\end{tabular}

with a positive result on one or the other sample. This definition of a positive individual is in agreement with the US Centers for Disease Control and Prevention (CDC) and the European Centre for Disease Prevention and Control (ECDC) directives on SARS-CoV-2 testing [24-26].

Secondary outcomes included the description of the studied population and the comparison between $\mathrm{Ct}$ values measured with NP and OS, an approximate proxy of viral loads.

To calculate the sample size in the absence of data regarding the sensitivity of OS in symptomatic subjects, we calculated the sensitivity of OS once the first 40 paired (NP-OS) samples were obtained. This sensitivity was $85 \%$. Given this estimate and a desired lower bound of the $95 \%$ confidence interval for sensitivity of at least $80 \%, 144$ volunteers were needed to complete the study in symptomatic subjects. To deal with the dropout risk we decided to include 149 symptomatic subjects.

\section{Statistics}

Continuous variables are presented as means $\pm \mathrm{sD}$, and categorical variables as numbers and percentages. Baseline characteristics between patients with and without COVID-19 were compared using the t-test or Wilcoxon-Mann-Whitney for quantitative variables based on the normality of the distribution of parameters or using the Chi-Square test for qualitative variables. The Shapiro-Wilk test was used to determine normality.

\section{Ethics and regulatory authorisations}

The promoter of the study was the Center Hospitalier Universitaire de Nice. The agreement for the study of the Institutional review board Sud Méditerranée V was obtained on April 22, 2020 (registration \# 20.04014.35208). SHAM liability insurance was obtained $\left(n^{\circ}\right.$ 159087). The study is registered in ClinicalTrial.gov (NCT04418206).

\section{Role of the funding sources}

The organisations that supported this study played no role in its design, patient selection, data collection, analysis or interpretation, report writing or decision to submit the document for publication. Authors had full access to all data and responsibility for submission for publication.

Results

425 subjects referred to the Nice-Côte d'Azur Metropolis free COVID-19 screening centre were approached to participate in the study, and 14 declined. Thus, 411 subjects underwent COVID-19 diagnostic testing over the 22 weeks of the study - 149 symptomatic subjects during the first part of the study and 262 close contacts during the second part of the study. Two symptomatic subjects declined to perform NP once OS had been performed and were excluded from subsequent analyses. One had a positive OS RT-PCR, and the other was negative. The study therefore covers the remaining 409 participants (figure 1). All 409 participants performed the salivary self-sampling with the OS correctly as explained.

The 147 symptomatic subjects were aged $40 \pm 15$ years and were predominantly women (86 out of 147, $58.5 \%$ ). The interval between symptom onset and testing was 3.6 \pm 2.6 days and most participants (107 out of $147,72.8 \%$ ) were sampled at the early stage of the disease, i.e., within 4 days of symptom onset. Of these symptomatic subjects, 59 (40.1\%) had a positive RT-PCR result with one or both of the sampling techniques and were thus diagnosed as having COVID-19. No clinical symptoms distinguished between RT-PCR positive and negative subjects (figure 2), with the exception of anosmia and dysgeusia, which were more frequent in RT-PCR positive subjects ( $42 \%$ versus $10 \%, \mathrm{p}<0.001$ and 38 versus $16 \%, \mathrm{p}=0.004$ ) 


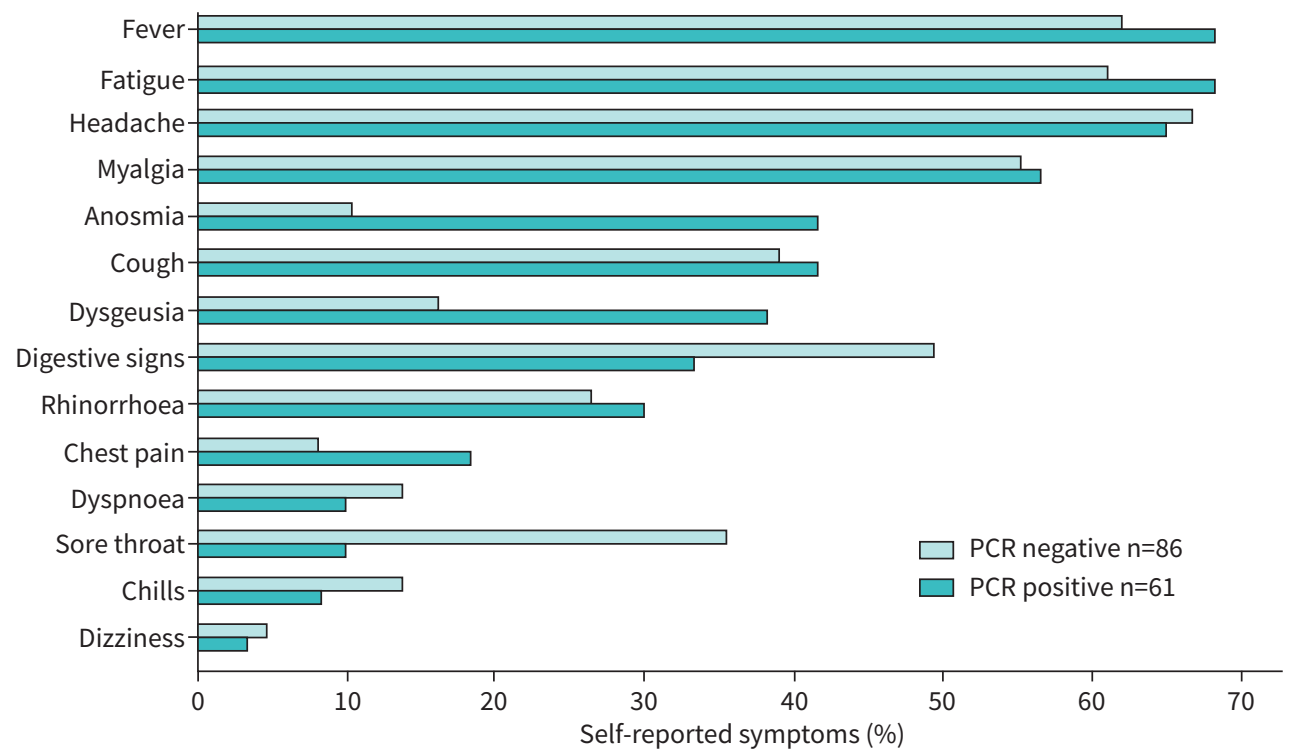

FIGURE 2 Self-reported symptoms.

and sore throat, which was significantly more common in RT-PCR negative subjects (36 versus $10 \%$, $\mathrm{p}=0.001)$.

In these symptomatic subjects, the Ct values for the Orf $1 \mathrm{~b}$ and $\mathrm{N}$ genes with OS showed a >3-point increase compared with NP; the magnitude of this difference indicates a $>10$-fold lower quantity of viral genetic material in OS samples [27] (figure 3).

The 262 close contacts with a laboratory-confirmed COVID-19 case were predominantly women (145 out of $262,55.3 \%)$. The mean age was $41 \pm 15$ years. The contact was identified as being in the household $(n=41 ; 15.6 \%)$, in the family $(n=56 ; 21.4 \%)$, in the close environment $(n=40 ; 15.3 \%)$, at work $(n=65$; $24.8 \%$ ) or was not known by the subject ( $n=60 ; 22.9 \%)$. Of these close contact subjects, $57(21.7 \%)$ had a positive RT-PCR result with one or both of the sampling techniques. Differences in viral load between the NP and the OS could not be assessed in close contact subjects since viral RNA detection with NP relied on TMA and not on RT-PCR in this part of the study. The viral strains identified during the study were almost exclusively $\beta$ and $\gamma$ variants.

In the symptomatic subjects, the NP-OS concordance was 96.5\% (95\% CI: 93.5-99.5) and the OS sensitivity was 93.2\% (95\% CI: 89.1-97.3) with the Idylla platform. With the Synlab Barla platform, the NP-OS concordance was $89.0 \%$ (95\% CI: 83.9-94.1) and the OS sensitivity was 76.3\% (95\% CI: 69.4-83.2) (table 1).

In the close contact subjects, the NP-OS concordance was 93.8\% (95\% CI: 90.9-96.7) and the OS sensitivity was $71.9 \%$ (95\% CI: 66.5-77.3) with the Idylla platform. With the Synlab barla platform, the NP-OS concordance was $94.2 \%$ (95\% CI: 91.4-97.0) and the OS sensitivity was $73.7 \%$ (95\% CI: 68.4-79.0) (table 2).

TABLE 2 Clinical performance of oral sponges (OS) compared to nasopharyngeal swabs (NP) for SARS-CoV-2 screening (external validation at the Synlab Barla laboratory platform)

\begin{tabular}{|c|c|c|c|c|c|c|c|c|}
\hline & $\begin{array}{l}\mathrm{NP}+ \\
\mathrm{OS}+ \\
a\end{array}$ & $\begin{array}{l}\mathrm{NP}+ \\
\mathrm{OS}- \\
b\end{array}$ & $\begin{array}{l}\mathrm{NP}- \\
\mathrm{OS}+ \\
\mathrm{C}\end{array}$ & $\begin{array}{l}\mathrm{NP}- \\
\mathrm{OS}- \\
d\end{array}$ & $\begin{array}{c}\text { Total } \\
n=a+b+c+d\end{array}$ & $\begin{array}{l}\text { Concordance \% } \\
(a+d) / n(95 \% \mathrm{Cl})\end{array}$ & $\begin{array}{l}\text { Sensitivity of NP \% } \\
(a+b) /(a+b+c)(95 \% \mathrm{Cl})\end{array}$ & $\begin{array}{l}\text { Sensitivity of OS \% } \\
(a+c) /(a+b+c)(95 \% \mathrm{Cl})\end{array}$ \\
\hline Symptomatic subjects & 43 & 14 & 2 & 87 & 146 & $89.0(83.9-94.1)$ & $96.6(93.7-99.5)$ & $76.3^{\#}(69.4-83.2)$ \\
\hline Close contact subjects & 42 & 15 & 0 & 205 & 262 & 94.2 (91.4-97.0) & 100 & $73.7(68.4-79.0)$ \\
\hline
\end{tabular}



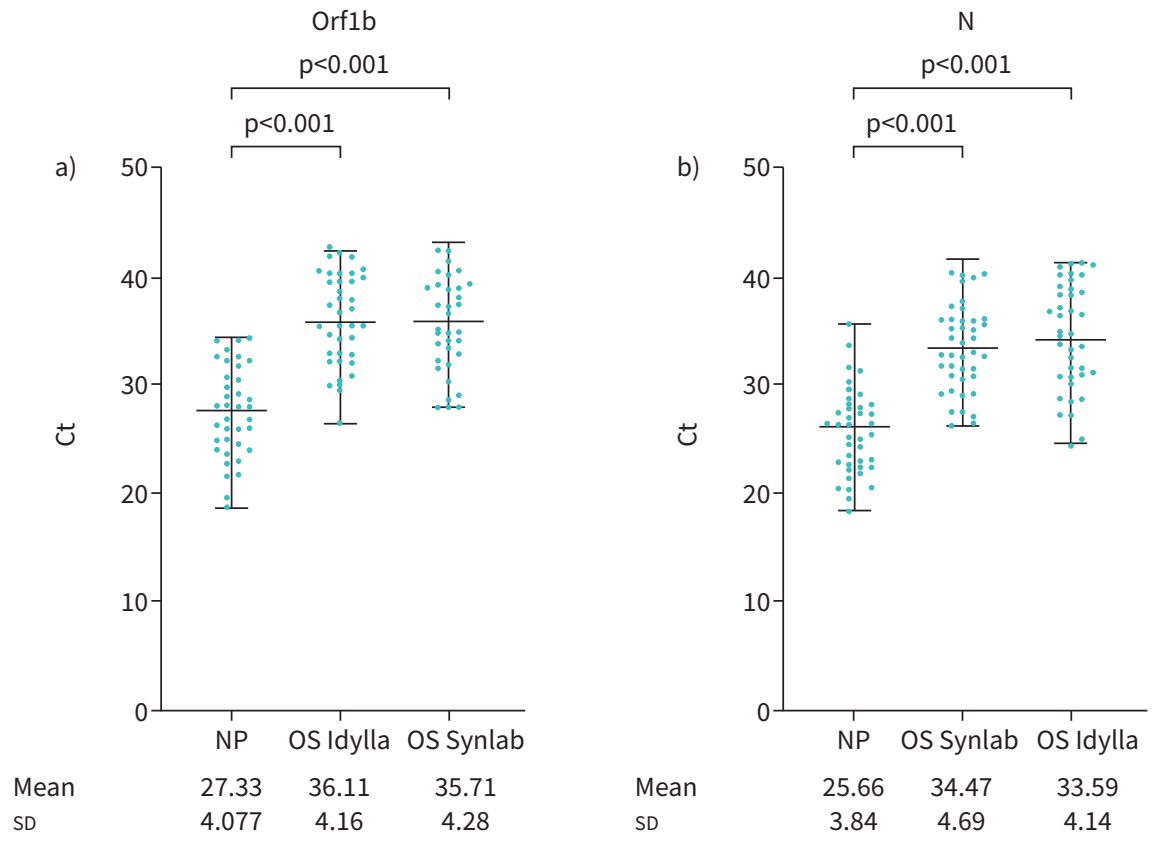

FIGURE 3 Viral load of nasopharyngeal swab (NP) and oral sponge (OS) as indirectly assessed by the cycle threshold (Ct) for the a) Orf1b and b) $\mathrm{N}$ genes.

\section{Discussion}

In this study, RT-PCR SARS-CoV-2 testing with OS showed a high level of concordance with NP testing (96.5\%, 95\% CI: 89.6-94.8) and a high sensitivity (93.2, 95\% CI: 89.1-97.3) for symptomatic subjects and a slightly lower level of concordance (93.8\%, 95\% CI: 90.9-96.7) and a slightly lower sensitivity (71.9\%, 95\% CI: 66.5-77.3) in asymptomatic close contacts of a laboratory-confirmed COVID-19 case. These results obtained in ambulatory subjects presenting to a public community-based screening centre strongly suggest that OS, a straightforward, low-cost and high-throughput sampling material, can be used for frequent RT-PCR testing of COVID-19 patients and mass screening of populations. To our knowledge, this is the first trial of OS sampling for SARS-CoV-2.

During the early phase of the COVID-19 pandemic, many molecular tests, immunoassays and sampling methods were rapidly developed and validated using archived biological samples of known virological status, albeit many still await clinical validation [28]. To evaluate the clinical performance of OS, compared to NP, the present study was carried out according to the standards recommended by the French "Haute Autorité de Santé" [16], i.e., a prospective comparative clinical study relating to a series of individuals of unknown COVID-19 status, recruited consecutively; a salivary test including at least two molecular targets; and by the US and European CDC directives, i.e., definition of a positive individual when comparing two diagnostic SARS-Cov-2 testing methods [26, 29, 30].

In published studies that compared salivary and NP testing, symptomatic subjects were the dominant inclusion profile (85\%), especially in the majority of short series of hospitalised patients [14]. Only six cohorts of equal or larger size than ours reported comparative test results obtained in a community-based settings [31-36].

Given the particularly high incidence of COVID-19 in the Nice metropolitan area throughout our study period (incidence between 330 and 720 per 100000), the high rate of positivity (21\% in asymptomatic contacts and $41 \%$ in symptomatic subjects) observed in the present study was higher than the rates observed in these six published cohorts (1.5 to 10.7\%) [16, 31-35]. Despite this difference, our NP-OS concordance and the sensitivity of RT-PCR on NP and on OS are in agreement with the results reported for these cohorts [26].

RT-PCR with OS performed at the Synlab Barla platform showed a significantly lower sensitivity than the Idylla platform in symptomatic subjects. This discrepancy may be due to two factors: the Idylla platform 


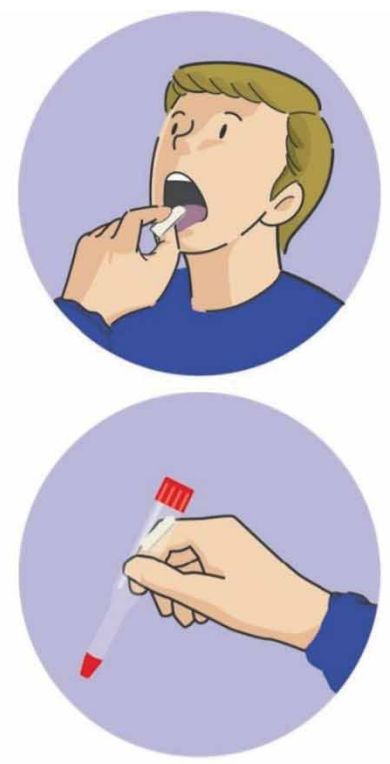

The sponge is put into the mouth

After screwing the top cap back on, the tube is shaken to bring the sponge into the middle of the tube

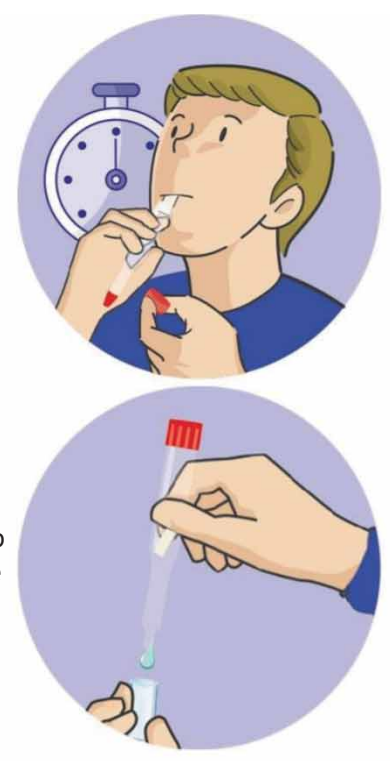

1 minute later, the sponge is carefully placed into the uncapped tube

FIGURE 4 All-in-one saliva sampling technique with a PVA sponge and a flexible, double-capped plastic tube.

uses three Orf1 and two $\mathrm{N}$ targets, while the Synlab Barla platform uses only one Orf1 and one N target; preservation at $-80^{\circ} \mathrm{C}$ for several weeks may have altered the nucleic acids. The discrepancy disappeared in the second part of the study in which the external validation of OS testing at the Synlab Barla platform was done on fresh samples in real time.

The significant difference in Cts, an approximate proxy for viral load, observed between paired samples from the nasopharyngeal and oral cavity in symptomatic subjects can be due to several parameters, notably endogenous to the laboratory (i.e., total volume of sample collection buffer/medium, sample preparation method (heat, lysis methods) and laboratory reagent volumes used in each step of the RT-PCR process. However, such a large difference is hardly explained by the experimental conditions and has also been observed by others $[2,29,37,38]$. This is why the diagnostic yield of NP is considered to be higher than that of throat swabs $[29,38]$. This difference most likely also has a pathophysiological basis, related to the fact that the mouth squamous cells act as a viral reservoir to a lesser degree than the nasopharynx ciliated cells $[19,20]$. As a consequence, the interpretative cut-offs for NP Ct [22] cannot apply to saliva samples.

The OS sampling method is well standardised. It does not need sialagogic drugs, nor clearing the throat or spitting effort, nor particular constraints such as early morning saliva sampling before tooth brushing and breakfast, avoiding eating, drinking, gum chewing, smoking or vaping [30,39]. It does not need dedicated trained nursing staff and its acceptability makes it possible to consider repeating the test even in institutionalised elderly people or in children.

The question as to whether the $72 \%$ sensitivity of OS we showed in symptomatic contact subjects is good enough to identify SARS-CoV-2-infected people in the setting of mass screening can be debated. As a comparison, in non-symptomatic subjects, the lateral-flow tests that are currently widely used because they can be performed with minimal supervision have a 35\% sensitivity; 95\% CI (27-44\%) for anterior nasal sampling and 51\% sensitivity; 95\% CI (22-80\%) for mid-turbinate sampling [8]. In a landmark position paper, Mina et al. [6] distinguished between low-frequency tests with high analytical sensitivity and high-frequency tests with low analytical sensitivity. According to this classification, RT-PCR on NP specimens belongs to the former category for symptomatic and non-symptomatic subjects. Importantly, RT-PCR on OS specimens would be considered as a high-frequency test with high analytical sensitivity in symptomatic subjects and as a high-frequency test with intermediate analytical sensitivity in non-symptomatic subjects.

We now recently industrialised the OS process in the form of an 'all-in-one' kit simplifying extraction of the biological liquid (figure 4). 
Acknowledgements: Special thanks to E. Faidhi, N. Fridlyand, A. Rauscher, E. Maris, the Lauro family and the many private donors for their generous contribution.

Provenance: Submitted article, peer reviewed.

Conflict of interest: J. Boutros has nothing to disclose. J. Benzaquen has nothing to disclose. C.H. Marquette has nothing to disclose. M. Ilié has nothing to disclose. M. Labaky has nothing to disclose. D. Benchetrit has nothing to disclose. T. Lavrut has nothing to disclose. S. Leroy has nothing to disclose. R. Chemla has nothing to disclose. M. Carles has nothing to disclose. V. Tanga has nothing to disclose. C. Maniel has nothing to disclose. O. Bordone has nothing to disclose. M. Allégra has nothing to disclose. V. Lespinet has nothing to disclose. J. Fayada has nothing to disclose. J. Griffonnet has nothing to disclose. V. Hofman has nothing to disclose. P. Hofman is a member of the scientific advisory board (group of European experts) of Biocartis; however, this board is totally independent of Biocartis.

Support statement: This work was supported by Conseil Départemental 06, Ville de Nice, Métropole Nice Côte d'Azur, Fonds de Dotation AVENI and private donors. Funding information for this article has been deposited with the Crossref Funder Registry.

\section{References}

1 Hanson KE, Caliendo AM, Arias CA, et al. Infectious Diseases Society of America Guidelines on the Diagnosis of COVID-19. Clin Infect Dis 2021; in press [https://doi.org/10.1093/cid/ciab048].

2 Zou L, Ruan F, Huang M, et al. SARS-CoV-2 viral load in upper respiratory specimens of infected patients. New Engl J Med 2020; 382: 1177-1179.

3 Sullivan PS, Sailey C, Guest JL, et al. Detection of SARS-CoV-2 RNA and antibodies in diverse samples: protocol to validate the sufficiency of provider-observed, home-collected blood, saliva, and oropharyngeal samples. JMIR Public Health Surveill 2020; 6: e19054.

4 Kucirka LM, Lauer SA, Laeyendecker $\mathrm{O}$, et al. Variation in false-negative rate of reverse transcriptase polymerase chain reaction-based SARS-CoV-2 tests by time since exposure. Ann Intern Med 2020; 173: 262-267.

5 Arevalo-Rodriguez I, Buitrago-Garcia D, Simancas-Racines D, et al. False-negative results of initial RT-PCR assays for COVID-19: a systematic review. PLOS ONE 2020; 15: e0242958.

6 Mina MJ, Parker R, Larremore DB. Rethinking Covid-19 test sensitivity - a strategy for containment. New Engl J Med 2020; 383: e120.

7 Goldfarb DM, Tilley P, Al-Rawahi GN, et al. Self-collected saline gargle samples as an alternative to health care worker-collected nasopharyngeal swabs for COVID-19 diagnosis in outpatients. J Clin Microbiol 2021; 59: e02427-20.

8 Haute Autorité de Santé. Évaluation de l'intérêt des tests antigéniques rapides (TDR/TROD) sur prélèvement nasal pour la détection du virus SARS-CoV-2 (Méta-analyse). 2021. www.has-sante.fr/jcms/p_3269794/fr/ evaluation-de-l-interet-des-tests-antigeniques-rapides-tdr/trod-sur-prelevement-nasal-pour-la-detection-duvirus-sars-cov-2-meta-analyse Date last updated: 2 June 2021. Date last accessed: 1 September 2021.

9 World Health Organization. Antigen-detection in the diagnosis of SARS-CoV-2 infection using rapid immunoassays: interim guidance, 11 September 2020. https:/www.who.int/publications-detail-redirect/ antigen-detection-in-the-diagnosis-of-sars-cov-2infection-using-rapid-immunoassays Date last updated: 11 September 2020. Date last accessed: 22 January 2021.

10 Butler-Laporte G, Lawandi A, Schiller I, et al. Comparison of saliva and nasopharyngeal swab nucleic acid amplification testing for detection of SARS-CoV-2: a systematic review and meta-analysis. JAMA Intern Med 2021; 181: 353-360.

11 Liu L, Wei Q, Alvarez X, et al. Epithelial cells lining salivary gland ducts are early target cells of severe acute respiratory syndrome coronavirus infection in the upper respiratory tracts of rhesus macaques. $J$ Virol 2011; 85: 4025-4030.

12 Lu B, Huang Y, Huang L, et al. Effect of mucosal and systemic immunization with virus-like particles of severe acute respiratory syndrome coronavirus in mice. Immunology 2010; 130: 254-261.

$13 \mathrm{Xu} \mathrm{H}$, Zhong L, Deng J, et al. High expression of ACE2 receptor of 2019-nCoV on the epithelial cells of oral mucosa. Int J Oral Sci 2020; 12: 1-5.

14 Haute Autorité de Santé. Méta-analyse de l'intérêt diagnostique des tests RT-PCR salivaires de détection du SARS-CoV-2. www.has-sante.fr/jcms/p_3237008/fr/meta-analyse-de-l-interet-diagnostique-des-tests-rt-pcrsalivaires-de-detection-du-sars-cov-2 Date last accessed: 10 April 2021.

15 Le Guludec Haute Autorité de Santé. Avis n²021.0007/AC/SEAP du 10 février 2021 du collège de la HAS relatif aux modifications des conditions d'inscription sur la LAP mentionnée à l'article L. 162-1-7 du CSS, à la détection du génome du virus SARS-CoV-2 par technique de transcription inverse suivie d'une amplification (RT-PCR) sur prélèvement salivaire. www.has-sante.fr/jcms/p_3236975/fr/avis-n-2021-0007/ac/seap-du-10- 
fevrier-2021-du-college-de-la-has-relatif-aux-modifications-des-conditions-d-inscription-sur-la-lap-mentionnee-al-article-l-162-1-7-du-css-a-la-detection-du-genome-du-virus-sars-cov-2-par-technique-de-transcriptioninverse-suivie-d-une-amplification-rt-pcr-sur-prelevement-salivaire Date last updated: 11 February 2021. Date last accessed: 7 April 2021.

16 Haute Autorité de Santé. Revue rapide sur les tests de détection antigénique du virus SARS-CoV-2. 8 October 2020. www.has-sante.fr/upload/docs/application/pdf/2020-10/synthese_tests_antigeniques_vd.pdf

17 Deprez M, Zaragosi L-E, Truchi M, et al. A single-cell atlas of the human healthy airways. Am J Respir Crit Care Med 2020; 202: 1636-1645.

18 Tanga V, Leroy S, Fayada J, et al. Establishment of a collection of blood-derived products from COVID-19 patients for translational research: experience of the LPCE Biobank (Nice, France). Biopreserv Biobank 2020; 18: 517-524.

19 Sungnak W, Huang N, Bécavin C, et al. SARS-CoV-2 entry factors are highly expressed in nasal epithelial cells together with innate immune genes. Nat Med 2020; 26: 681-687.

20 Ziegler CGK, Allon SJ, Nyquist SK, et al. SARS-CoV-2 receptor ACE2 is an interferon-stimulated gene in human airway epithelial cells and is detected in specific cell subsets across tissues. Cell 2020; 181: 1016-1035.e19.

21 l'Assurance Maladie. Contact tracing: arrêter les chaînes de transmission [Internet]. www.ameli.fr/assure/ covid-19/tester-alerter-proteger-comprendre-la-strategie-pour-stopper-lepidemie/contact-tracing-arreter-leschaines-de-transmission Date last accessed: 13 April 2021.

22 Société Française de Microbiologie. Avis du 25 septembre 2020 de la Société Française de Microbiologie (SFM) relatif à l'interprétation de la valeur de Ct (estimation de la charge virale) obtenue en cas de RT-PCR SARS-CoV-2 positive sur les prélèvements cliniques réalisés à des fins diagnostiques ou de dépistage. Version 3 [Internet]. 2020. www.sfm-microbiologie.org/wp-content/uploads/2020/10/Avis-SFM-valeur-Ct-excre\%CC\% 81tion-virale-_-Version-Finale-07102020-V3.pdf Date last accessed: 22 January 2021.

23 Hofman P, Boutros J, Benchetrit D, et al. A rapid near-patient RT-PCR test for suspected COVID-19: a study of the diagnostic accuracy. Ann Transl Med 2021; 9: 921.

24 CDC. Healthcare Workers. Centers for Disease Control and Prevention 2020. www.cdc.gov/coronavirus/2019ncov/hcp/testing-overview.html Date last updated: 12 April 2021.

25 Diagnostic testing and screening for SARS-CoV-2 [Internet]. European Centre for Disease Prevention and Control. www.ecdc.europa.eu/en/covid-19/latest-evidence/diagnostic-testing Date last updated: 12 April 2021.

26 Ibrahimi N, Delaunay-Moisan A, Hill C, et al. Screening for SARS-CoV-2 by RT-PCR: Saliva or nasopharyngeal swab? Rapid review and meta-analysis. PLOS ONE 2021; 16: e0253007.

27 Public Health England. Understanding cycle threshold (Ct) in SARS-CoV-2 RT-PCR. https://assets.publishing. service.gov.uk/government/uploads/system/uploads/attachment_data/file/926410/Understanding_Cycle_ Threshold__Ct_in_SARS-CoV-2_RT-PCR_.pdf Date last updated: October 2020. Date last accessed: 1 September 2021.

28 Vandenberg O, Martiny D, Rochas O, et al. Considerations for diagnostic COVID-19 tests. Nat Rev Microbiol 2020; 18: 1-13.

29 Patel MR, Carroll D, Ussery E, et al. Performance of oropharyngeal swab testing compared with nasopharyngeal swab testing for diagnosis of Coronavirus Disease 2019-United States, January 2020February 2020. Clin Infect Dis 2020; 72: 482-485. [cited 2021 Feb 8]; www.ncbi.nlm.nih.gov/pmc/articles/ PMC7337670/.

30 L'Helgouach N, Champigneux P, Schneider FS, et al. EasyCOV: LAMP based rapid detection of SARS-CoV-2 in saliva. medRxiv 2020; pre-print [https://doi.org/10.1101/2020.05.30.20117291].

31 Caulley L, Corsten M, Eapen L, et al. Salivary Detection of COVID-19. Ann Intern Med 2020; 174: 131-133.

32 Barat B, Das S, Giorgi VD, et al. Pooled saliva specimens for SARS-CoV-2 testing. J Clin Microbiol 2021; 59: e02486-20.

33 Kandel C, Zheng J, McCready J, et al. Detection of SARS-CoV-2 from saliva as compared to nasopharyngeal swabs in outpatients. Viruses 2020; 12: 1314.

34 Senok A, Alsuwaidi H, Atrah Y, et al. Saliva as an alternative specimen for molecular COVID-19 testing in community settings and population-based screening. IDR 2020; 13: 3393-3399.

35 Vogels CBF, Watkins AE, Harden CA, et al. SalivaDirect: a simplified and flexible platform to enhance SARS CoV-2 testing capacity. Med 2021; 2: 263-280.

36 Yokota I, Shane PY, Okada K, et al. Mass screening of asymptomatic persons for SARS-CoV-2 using saliva. Clin Infect Dis 2021; 73: e559-e565.

37 Vlek ALM, Wesselius TS, Achterberg R, et al. Combined throat/nasal swab sampling for SARS-CoV-2 is equivalent to nasopharyngeal sampling. Eur J Clin Microbiol Infect Dis 2021; 40: 193-195.

38 Wang X, Tan L, Wang X, et al. Comparison of nasopharyngeal and oropharyngeal swabs for SARS-CoV-2 detection in 353 patients received tests with both specimens simultaneously. Int $J$ Infect Dis 2020; 94: 107-109.

39 Lai CKC, Chen Z, Lui G, et al. Prospective study comparing deep throat saliva with other respiratory tract specimens in the diagnosis of Novel Coronavirus Disease 2019. J Infect Dis 2020; 222: 1612-1619. 